\title{
Chlorophyll fluorescence in rice: probing of senescence driven changes of PSII activity on rice varieties differing in grain yield capacity
}

\author{
Antelmo R. Falqueto ${ }^{1}$, Fabio S. P. Silva ${ }^{2}$, Daniela Cassol' ${ }^{2}$, Ariano M. Magalhães Júnior ${ }^{3}$ \\ Antônio C. Oliveira ${ }^{4}$ and Marcos A. Bacarin ${ }^{*}$
}

${ }^{1}$ Universidade Federal do Espírito Santo, Departamento de Ciências da Saúde, Biológicas e Agrárias, Rodovia BR 101 Norte, Km 60, Bairro Litorâneo, CEP 29932-540 São Mateus, ES, Brazil. e-mail: antelmofalqueto@yahoo.com.br

${ }^{2}$ Universidade Federal de Pelotas (UFPel), Departamento de Botânica, Instituto de Biologia, CEP 96010-900 Pelotas, RS, Brazil. e-mail: fabiopaulin@msn.com, danicassol@gmail.com, bacarin@ufpel.edu.br

${ }^{3}$ Embrapa Clima Temperado, Caixa Postal 403, CEP 96001-970 Pelotas, RS, Brazil. E-mail: ariano@cpact.embrapa. br ${ }^{(4)}$ UFPel, Faculdade de Agronomia Eliseu Maciel, Departamento de Fitotecnia. e-mail: acosta@ufpel.edu.br

*Corresponding author: bacarin@ufpel.edu.br; phone: +55 53 32757336, fax: + 555332757316
Received: 01 February 2010; Accepted: 11 April 2010

\begin{abstract}
With Japonica rice BRS Firmeza and indica rice BRS Pelota (low and high grain yield, respectively) as materials, Chl content and $\mathrm{Chl}$ a fluorescence parameters in flag leaves from the heading to mature grain stage were investigated. The $\mathrm{Chl}$ content and the Chl a fluorescence were measured using a portable chlorophyll meter CL-01 and portables fluorometer Handy-PEA and FMS-2 (Hansatech, Kings Lynn, UK), respectively. All measurements were taken on middle part of the flag leaves $(n=10)$. The results showed that the $\mathrm{Chl}$ content and $\mathrm{Chl}$ a fluorescence parameters declined after full expansion of flag leaves in both rice cultivars. However, these biochemical and photochemical parameters did not show similar changing pattern and the behavior of flag leaves senescence showed some differences between BRS Pelota and BRS Firmeza rice cultivars. During the senescence of flag leaves, BRS Pelota, the rice cultivar with higher grain yield capacity, was characterized by significant reductions in Chl content, $\mathrm{Pl}_{\mathrm{ABS}, \text { Total, }}$ $\mathrm{TR}_{0} / \mathrm{ABS}, \mathrm{ET} / \mathrm{ABS}, \mathrm{ET}_{0} / \mathrm{TR}_{0}, \mathrm{RC} / \mathrm{ABS}$ compared to BRS Firmeza. On the other hand, $\mathrm{DI}_{0} / \mathrm{RC}, \mathrm{TR}_{0} / \mathrm{RC}$ and $\mathrm{ET} / \mathrm{RC}$ were significantly higher in BRS Pelota. These results show that the decreased photosystem II activity, evaluated through chlorophyll fluorescence analysis, was resultant of leaves senescence process, which was much more expressive in BRS Pelota rice variety. We suggest that the higher productivity of BRS Pelota rice cultivar results from its higher assimilate mobilization ability or energy usage efficiency, in despite of its lower light absorption capacity.
\end{abstract}

Key words: JIP-test, non-photochemical quenching coefficient, Oryza sativa, performance index, PSIl photochemical efficiency, stay green mutant rice.

Abbreviations: $\mathrm{ABS} / \mathrm{RC}$, absorption flux per $\mathrm{RC}$; Chl, chlorophyll; $\mathrm{DAH}$ - days after heading; $\mathrm{Dl}_{0} / \mathrm{RC}$, dissipated energy flux per $\mathrm{RC}$; $E T$, conversion of excitation energy to electron transport; $E T_{0} / R C$, Electron transport flux per $R C ; T_{0} / A B S=\phi_{E_{0}}$, quantum yield of electron transport; $F_{0}, F_{V}$, and $F_{M}-$ minimal, variable and maximum Chl fluorescence of PSIl in the dark adapted state; $F_{V} / F_{M}=\phi_{P_{0}}=$ $\mathrm{TR}_{0} / \mathrm{ABS}$, maximal efficiency of PSIl photochemistry; $\mathrm{F}_{0}{ }^{\prime}, \mathrm{F}_{\mathrm{v}}{ }^{\prime}$ and $\mathrm{F}_{\mathrm{M}}{ }^{\prime}$ - minimal, variable and maximum Chl fluorescence in the light adapted state; $F_{v}{ }^{\prime} / F_{M}$ ', efficiency of excitation capture by open PSIl reaction centers; $L D$ - constitutive non-photochemical loss in the dark; LNP, non-photochemical loss in PSIl; NPQ, Stern-Volmer quenching; qP, photochemical quenching; qN, non-photochemical 
quenching, $\phi_{P S I I}$, actual PSII efficiency; $\mathrm{P}_{\mathrm{ABS}, \text { Total, }}$, total performance index, measuring the performance up to the PSI end electron acceptors; PSI, photosystem I; PSII, photosystem II; $Q_{A}$, electron acceptor of PSII; qP, photochemical quenching coefficient; RC/ $A B S$, ratio of reaction centers and the absorbance; $R E_{0} / T R_{0}=\delta_{R 0}$, efficiency with which an electron can move from the reduced intersystem electron acceptors to the PSI end electron acceptors; TR, trapping of excitation energy; $T R_{0} / R C$, trapped energy flux per RC; $\phi_{P S I I}$, actual PSII efficiency; $\phi_{D o}$ quantum yield of dissipation; $\phi_{R O}$, quantum yield for the reduction of end acceptors of PSI per photon absorbed; $R E_{0} / T R_{0}=\rho_{0}$, efficiency which a trapped exciton can move an electron into the electron transport chain from $Q_{A}$ to the end electron acceptors of PSI; $\Psi_{0}=\mathrm{ET}_{0} / \mathrm{TR}_{0}$, yield of electron transport per trapped exciton.

\section{INTRODUCTION}

Leaf senescence is the sequence of biochemical and physiological events comprising the final stage of development (Jiao et al., 2003; Tang et al., 2005). The most striking event in leaf senescence is the disassembly of the photosynthetic apparatus with subsequent decrease in photosynthetic capacity (Lu et al., 2002; Weng et al., 2005). Previous studies have been shown that decreased photosynthetic capacity in senescent leaves may be associated with reduced photochemical activities of photosystems (Lu et al., 2002). Many studies relating the biochemical changes that occur during leaf senescence has focused on loss of photosynthetic pigments, degradation of protein, and re-absorption of mineral nutrients. Therefore, the drastic decline in activities of PSII, PSI and whole chain electron transport has also been reported in several senescing systems, indicating that the photochemical activity inhibits photosynthesis during leaf senescence (Zhang et al., 2006).

Among the experimental techniques available for investigation of photosynthetic activity in plants, Chl a fluorescence can be an excellent tool, giving us informations on the relationship between structure (molecular composition and conformation) and function of PSII. The use of this method to assess PSII photochemistry during leaf senescence in cultivars with differences in grain yield potential is important because it gives new insights about the fundamental processes of energy absorption and excess excitation energy use and dissipation by PSII in cereal crop plants during senescence. Moreover, such as already related in previous study, the leaf senescence pattern is variable and differences in leaf senescence should exist among cultivars with differences in grain yield (Falqueto et al., 2009a). In the present study, the fluorescence analysis according to so-called JIP-test will be used to compare the polyphasic rise of Chl a fluorescence between two rice cultivars differing in grain yield. This technical has been developed to investigate the "vitality" of plants in vivo and how it response to different environmental conditions (Srivastava and Strasser, 1996; Tsimilli-Michael and Strasser, 2008).
Efforts have been devoted to identify differences in chlorophyll fluorescence yield among rice varieties with differences in yield potential (Jiang et al., 2002). However, as far as Chl fluorescence parameters are concerned, the authors focused mainly on $F_{v} / F_{m}$ and/or effective quantum yield of PSII (申PSII) (Lu et al., 2002; Jiang et al., 2002; Rapacz, 2007). Besides, the existing studies on the changes in Chl fluorescence parameters in rice with senescence were conducted on primary leaves or cotyledons (Yordanov et al., 2008; Mishev et al., 2009). Studies conducted on flag leaves of rice are still not available. Thus, the results obtained should give detailed information on the fundamental processes of energy absorption, utilization and dissipation of excess excitation energy by PSII during senescence of flag leaves in distinct rice varieties.

The aim of this study was to compare the physiological changes that occur on flag leaves of rice varieties during senescence. For this purpose, we made measurements of transient and modulated chlorophyll fluorescence and chlorophyll index of two rice varieties differing in grain yield potential (O. sativa subsp. indica BRS Pelota cultivar - high grain production and 0 . sativa subsp. Japonica BRS Firmeza cultivar - low grain production).

\section{MATERIAL AND METHODS}

Plant material: This experiment was carried during rice (Oryza sativa L.) growing season (October to March) during the summer 2007/2008 at the greenhouse of Institute of Botany, Federal University of Pelotas, Brazil (31048'S, 52024'W). The rice varieties used were BRS Firmeza ( 0 . sativa subsp. Japonica) and BRS Pelota (0. sativa subsp. Indica). These cultivars were chosen because of their difference in grain yield potential (7.5 and $10 t$ ha $^{-1}$ for BRS Firmeza and BRS Pelota, respectively). BRS Firmeza is a stay green mutant rice included in the modern/ american rice. BRS Pelota is originated through the selection of off-type plants found in a heterogeneous population of BR-Irga 410 cultivar. A randomized complete design with ten replicates 
was used for each rice cultivar. Each replicate consisted of one plastic pot $(12 \mathrm{~L})$ filled with soil fertilized according to official guidelines. Twenty-five seeds were sown in each pot. In order to obtain uniform plants, the seedlings of each pot were thinned from 25 to 5 per pot after the appearance of the second leaf. Thereafter, a water depth of 3 to $5 \mathrm{~cm}$ was maintained until after maturity. Flag leaves were sampled from the point of emergence of the head from its sheath (arbitrarily designated day 1) through senescence. All measurements were taken on middle part of the flag leaves. Ten replications of each parameter for each age were performed.

Chl content: The Chl content was estimated by portable chlorophyll meter (CL-01, Hansatech, Kings Lynn, UK). The results were express such as "chlorophyll index" (Cassol et al., 2008).

Chl transient fluorescence - JIP test: Polyphasic Chl a fluorescence transient (OJIP) was measured by means of Handy-PEA (Hansatech, Kings Lynn, UK). Before all measurements, leaves were dark-adapted for 20 min. Light intensity was $3000 \mu \mathrm{mol} \mathrm{m}{ }^{-2} \mathrm{~s}^{-1}$, provided by an array of three high-intensity light-emitting diodes. The JIP-test (Strasser et al., 2004) was used to analyze each Chl a fluorescence transient. The concept of the JIP-test is based on the Energy Flux Theory in Bio-membranes (Strasser, 1981). These parameters provide structural and functional informations (such as specific and phenomenological fluxes, quantum yield or "vitality" indexes). The use of minimal $\left(F_{0}\right)$ and maximal $\left(F_{m}\right)$ fluorescence leads to the well accepted expression for the maximum quantum yield of primary photochemistry as $\mathrm{TR}_{0} / \mathrm{ABS}=1-\left(\mathrm{F}_{0} / \mathrm{F}_{\mathrm{m}}\right)=\mathrm{F}_{\mathrm{v}} / \mathrm{F}_{\mathrm{m}}$. For the detailed review on JIPtest parameters see Tsimilli-Michael and Strasser (2008). The performance index $\left(\mathrm{Pl}_{\mathrm{ABS}, \text { Total }}\right)$ (Tsimilli-Michael and Strasser, 2008) was introduced as a parameter to quantify the effects of environmental factors on photosynthesis in several studies.

Modulated Chl a fluorescence parameters: Modulated $\mathrm{Chl}$ a fluorescence was measured at room temperature with a portable fluorometer FMS-2 (Hansatech, Kings Lynn, UK) according experimental protocol described by Genty et al. (1989) and Roháček (2002). We measured minimal fluorescence $\left(\mathrm{F}_{0}\right)$ and maximal fluorescence $\left(\mathrm{F}_{\mathrm{m}}\right)$ levels. Then, the leaves were continuously illuminated with a white actinic light $\left(200 \mu \mathrm{mol} \mathrm{m} \mathrm{m}^{-2} \mathrm{~s}^{-1}\right)$. The steady-state of fluorescence $\left(F_{s}\right)$ was thereafter recorded and a second saturating pulse at $3000 \mu \mathrm{mol} \mathrm{m}{ }^{-2} \mathrm{~s}^{-1}$ was imposed to determine the maximal fluorescence level in light-adapted leaves $\left(F_{m}{ }^{\prime}\right)$. Then, the actinic light was removed and the minimal fluorescence level in the light-adapted state $\left(F_{0}{ }^{\prime}\right)$ was determined through of illuminating the leaf with $1 \mathrm{~s}$ of far-red light. Using both light and dark fluorescence parameters, we calculated: a) effective efficiency of PSII photochemistry, when PSII reaction centers were open $\left.\left(F_{\mathrm{v}}{ }^{\prime} / F_{\mathrm{m}}{ }^{\prime}\right), b\right)$ the actual PSII efficiency $\left(\phi_{\text {PSII }}\right)$, c) photochemical quenching coefficient ( $\mathrm{qP}$ ) (Genty et al., 1989), d) the non-photochemical quenching coefficient (qN) (Genty et al., 1989), e) the Stern-Volmer quenching (NPQ) (Bilger and Bjorkman, 1990; Demmig-Adams, 1990), f) nonphotochemical loss in PSII in dark-adapted state $\left[\mathrm{LD}=\mathrm{F}_{\mathrm{o}} / \mathrm{F}_{\mathrm{m}}\right]$ as introduced by Rohacek (2002), and g) non-photochemical loss in PSII [ $\left.L_{N P}=F_{o} / F_{m}{ }^{\prime}\right]$, (Stefanov and Terashima, 2008).

\section{RESULTS AND DISCUSSION}

Senescence of flag leaves in two rice varieties differing in grain yield capacity was characterized by $\mathrm{Chl}$ loss (leaf yellowing), as well as decreases in activities of photosynthetic electron transport, evaluated thought $\mathrm{Chl}$ a fluorescence measurements. However, these photochemical and biochemical parameters did not show similar changing pattern and the behavior of flag leaves senescence showed some differences between BRS Pelota and BRS Firmeza rice cultivars. Chl index differed between rice cultivars during natural senescence (Figure 1A). Leaf $\mathrm{Chl}$ content of BRS Firmeza was significantly greater from 8 until around the 36 days after heading (DAH), after which they maintained without greatest variations with senescence. $\mathrm{Chl}$ index values increased gradually in BRS Firmeza until $14 \mathrm{DAH}$.

Since several decades, the degree of Chl loss has been strongly associated with light-saturated photosynthetic reaction during heading in rice (Jião et al., 2003). In the present study, the higher Chl content in BRS Firmeza during the flag leaf senescence shows that the process of leaf senescence in BRS Firmeza was delayed compared with the earlier senescent rice variety BRS Pelota. Thus, our results indicate that leaf senescence in BRS Firmeza was prolonged under natural conditions. BRS Firmeza is a stay green mutant rice, characterized by the persistence of the green color of leaves for longer than BRS Pelota rice variety.

It was observed a significant increase in $A B S / R C$ in both rice cultivars after $25 \mathrm{DAH}$ (Figure 1B). No difference in ABS/RC was observed between the cultivars. The performance index $\left(\mathrm{Pl}_{\mathrm{ABS} \text {, Total }}\right)$, which illustrate the vitality of photosynthetic apparatus (Tsimilli-Michael and Strasser, 2008), differed between the cultivars analyzed. In BRS Pelota rice cultivar, no significant variation of $\mathrm{Pl}_{\mathrm{ABS} \text {,Total }}$ was observed until $39 \mathrm{DAH}$. However, after this date $\mathrm{Pl}_{\mathrm{ABS} \text {,Total }}$ decreased significantly. In contrast, BRS 
Firmeza was characterized by an markedly increase in $\mathrm{Pl}_{\mathrm{ABS}, \text { Total }}$ after $1 \mathrm{DAH}$, which was maintained without greater variations until 25 DAH (Figure 1C). Reduced $\mathrm{Pl}_{\mathrm{ABS} \text {, Total }}$ Values were obtained in BRS Firmeza after $25 \mathrm{DAH}$ (Figure 1C).
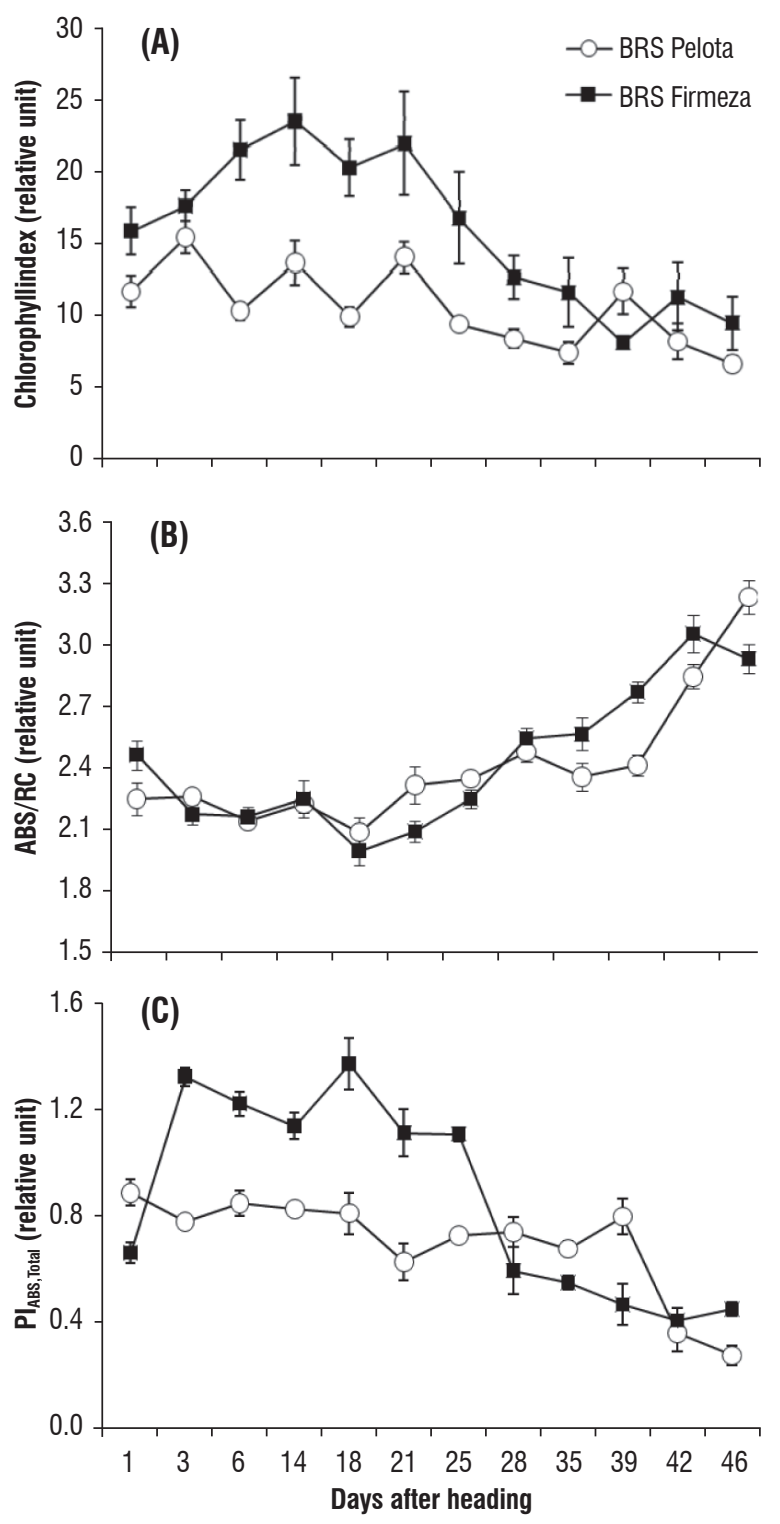

Figure 1. Chlorophyll content (A) estimated by portable chlorophyll meter and express such as "chlorophyll index", size of antenna complexes of PSII $(\mathrm{ABS} / \mathrm{RC})(\mathrm{B})$, and total performance index $\left(\mathrm{Pl}_{\mathrm{ABS} \text {,Total }}\right)(\mathrm{C})$ during flag leaf senescence of BRS Pelota, a high yield rice variety (open circle) and BRS Firmeza (filled square), a low yield rice variety rice. Values represent \pm S.E. of ten independent samples at the same time.

Modulated $\mathrm{Chl}$ a fluorescence measurements were also performed on dark-adapted attached flag leaves of BRS Firmeza (low grain yield) and BRS Pelota (high grain yield) rice cultivars. Measurements were made on the $1^{\text {st }}, 18^{\text {th }}, 35^{\text {th }}$ and $46^{\text {th }}$ days after heading, corresponding to developmental stages R4 - Heading, R5 - Milk stage, R6 - Dough stage and R7 - Mature grain (Counce et al., 2000).

The Figure 2A shows biophysical parameters relative to PSIl behaviour pattern: $\mathrm{Pl}_{A B S, \text { Total, }}$ the efficiencies/fluxes ratios $\mathrm{TR}_{0} / \mathrm{ABS}, \mathrm{ET} / \mathrm{ABS}, \mathrm{ET}_{0} / \mathrm{TR}_{0}$ and $\mathrm{RE}_{0} / \mathrm{TR}_{0}$, the specific fluxes for trapping $\mathrm{TR}_{0} / \mathrm{RC}$ and electron transport $\mathrm{ET}_{0} /$ $\mathrm{RC}$, and the amount of photosynthetic reaction centres per absorption RC/ABS. In Figure 2 each chlorophyll fluorescence parameter was normalised according the control values (the data related to $1^{\text {st }}$ day were used as control). The energy fluxes are: for absorption (ABS); trapping $\left(\mathrm{TR}_{0}\right)$, i.e. reduction of Pheo (pheophytin) and $Q_{A}$; electron transport $\left(E T_{0}\right)$ from $Q_{A}{ }^{-}$to the intersystem electron acceptors - EA: $Q_{B}$ (secondary electron quinone acceptor, $P Q$ (plastoquinone), Cyt (cytochrome $b_{6} / f$ ) and $\mathrm{PC}$ (plastocyanin); reduction $\left(\mathrm{RE}_{0}\right)$ of end acceptors at the PSI electron acceptor side: NADP (nicotinamide adenine dinucleotide phosphate) and $\mathrm{Fd}$ (ferredoxin) (TsimilliMichael and Strasser, 2008).

Themaximum quantumyield of primary photochemistry ( $\left.T R_{0} / A B S\right)$, often the only fluorescence parameter used to gauge the occurrence and extent of physiological changes in plants, can be quite insensitive to change (TsimilliMichael and Strasser, 2008). In contrast, in the present study, the slight decrease in $\mathrm{TR}_{0} / \mathrm{ABS}$ values was observed in both rice varieties at $46 \mathrm{DAH}$, as seen in Figure 2. However, in BRS Pelota, the rice cultivar disproved of stay green genes, $T_{0} / A B S$ values were much more reduced. In Addition, $\mathrm{TR}_{0} / \mathrm{RC}$ showed a significantly increase at 48 DAH. This increase was more evident in BRS Pelota than in BRS Firmeza. The behavior pattern of $\mathrm{TR}_{0} / \mathrm{RC}$ was also reflected in the increased values of effective antenna size per RC (ABS/RC - see Figure 1B). In BRS Pelota, the slower increase in $E T_{0} / R C$ at $48 \mathrm{DAH}$ resulted from an increase in trapping $\left(\mathrm{TR}_{0} / \mathrm{RC}\right)$ and not from a reduction in the electron transport capacity $\left(\mathrm{ET}_{0} / \mathrm{TR}_{0}\right)$.

In BRS Pelota the efficiency with which a trapped exciton can move an electron into the electron transport chain from $Q_{A}{ }^{-}$to the intersystem electron acceptors $\left(\mathrm{ET}_{0} /\right.$ $\mathrm{TR}_{0}$ ) and the quantum yield of electron transport from $Q_{A}{ }^{-}$to the intersystem electron acceptors (ET/ABS) were reduced in BRS Pelota at $46 \mathrm{DAH}$. In BRS Firmeza this 
parameters remained unchanged, except at $18 \mathrm{DAH}$ (Figure 2B). The efficiency which an electron can be moved from the reduced intersystem electron acceptors to the end electron acceptors of $\mathrm{PSI}\left(\mathrm{RE}_{0} / \mathrm{ET}_{0}\right)$, the quantum yield of electron transport from $Q_{A}{ }^{-}$to the end electron acceptors of $\mathrm{PSI}\left(\mathrm{RE}_{0} / \mathrm{ABS}\right)$, the efficiency which a trapped exciton can move an electron into the electron transport chain from $Q_{A}{ }^{-}$ to the end electron acceptors of PSI $\left(\mathrm{RE}_{0} / \mathrm{TR}_{0}\right)$ decreased with senescence in both rice cultivars (Figure 2). However, the main difference between the rice cultivar was related to

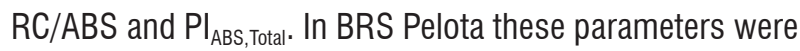
much more affected by senescence, while in BRS Firmeza there was an increased values of $\mathrm{RC} / \mathrm{ABS}$ and $\mathrm{PI}_{\mathrm{tot}, \mathrm{ABS}}$ only at $18 \mathrm{DAH}$. Thereafter, the specific fluxes (per RC), as well as the phenomenological fluxes (per cross section $=\mathrm{CS}$ ) were not varied between rice cultivars except the heat dissipation capacity ( $\mathrm{DI}_{0} / \mathrm{RC}$ ) (data not shown). $\mathrm{DI}_{0} /$
$\mathrm{RC}$ was higher in BRS Pelota at $46 \mathrm{DAH}$ (developmental stage $R_{7}$ ), period that coincides with the decreased values of chlorophyll index and $\mathrm{PI}_{\mathrm{ABS} \text {, Total }}$. Also, high values of $\mathrm{DI}_{0} /$ $\mathrm{RC}$ have been associated to occurrence of photoinhibition. To date, photoinhibition has been conveniently measured as a lowering of the $\mathrm{TR}_{0} / \mathrm{ABS}$ ratio following sufficient dark adaptation (Demmig and Björkman, 1987). $\mathrm{Dl}_{0} / \mathrm{RC}$ indicates the rate of the total dissipation of untrapped excitation energy from all RCs with respect to the number of active RCs. Dissipation in this context refers to the loss of absorbed energy through heat, fluorescence and energy transfer to other systems (Strasser et al., 2004) Therefore, dissipation can be also thought of as the absorption of photons in excess of what can be trapped by the RC. The $\mathrm{DI}_{0} / \mathrm{RC}$ values can be influenced by the ratio of active/ inactive RCs. Thus, analyzing the $\mathrm{DI}_{0} / \mathrm{RC}$ values we can predict the proportion of RCs inactive in a sample.
(A)

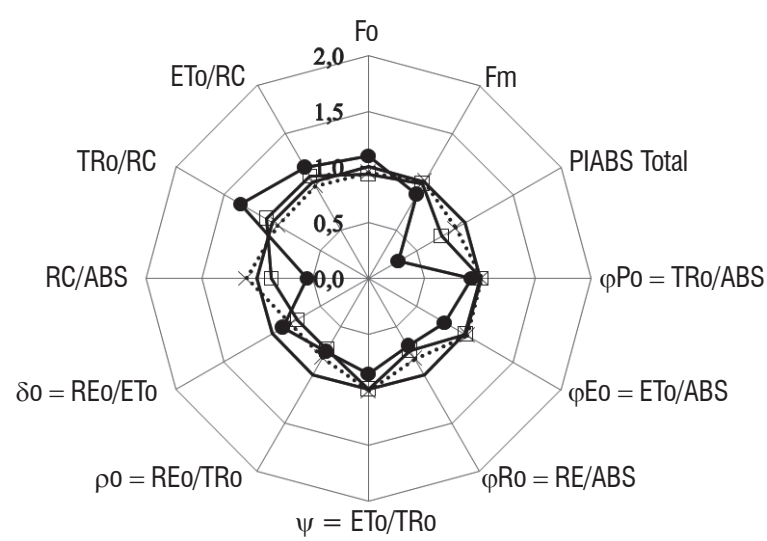

(B)

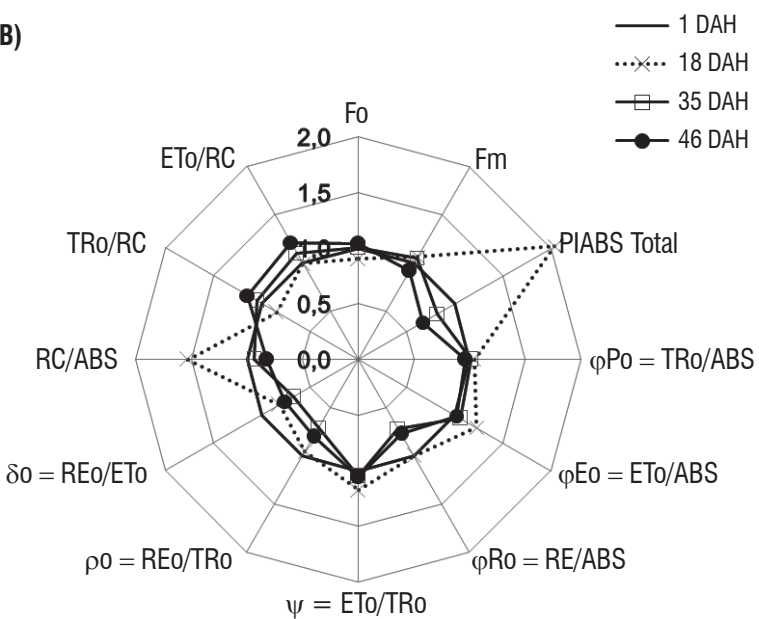

Figure 2. Influence of leaf senescence on several selected functional and structural JIP-test parameters plotted (radarplot center $=0.0$, maximum $=2.0$ ) relative to their respective controls (set as reference dashed circle $=1.0$ ) during flag leaf senescence of BRS Pelota (high yield, A) and BRS Firmeza (low yield, B). Measurements were made on the $1^{\text {st }}, 18^{\text {th }}, 35^{\text {th }}$ and $46^{\text {th }}$ days after heading (DAH), corresponding to developmental stages $R_{4}, R_{5}, R_{6}$ and $R_{7}$. Relative values are calculated from averages of 10 plants for each rice variety. 
From our results, we observed a greater variation of $\mathrm{F}_{\mathrm{v}}$ '/ $F_{m}{ }^{\prime}$ and $\phi_{P S \mid I}$ values in both rice varieties with senescence. $F_{v}{ }^{\prime} /$ $F_{m}{ }^{\prime}$ and $\phi_{P S \mid l}$ decreased significantly from $8 \mathrm{DAH}$ until $18 \mathrm{DAH}$, increasing again until $38 \mathrm{DAH}$ at which point it decreased significantly until $48 \mathrm{DAH}$ (Figure 3). Note that the variations in $\mathrm{F}_{\mathrm{v}}{ }^{\prime} / \mathrm{F}_{\mathrm{m}}{ }^{\prime}$ approximately paralleled the variations in effective quantum yield of photochemical energy conversion in PSII ( $\left.\phi_{\text {PSII }}\right)$ in BRS Pelota and BRS Firmeza. Therefore, this variation was similar between rice varieties, showing that the two rice varieties present the same efficiency of use the excitation energy during the light-adapted state. According to Stefanov and Terashima (2008), decreases in $F_{\mathrm{v}}{ }^{\prime} / F_{\mathrm{m}}{ }^{\prime}$ and $\phi_{\mathrm{PSII}}$ could be associated with an increased non-photochemical loss. However, in this study, no clear relationship was observed between $F_{v}{ }^{\prime} / F_{m}$ ' and $\phi_{\text {PSII }}$ values and those non-photochemical quenching (qNP). In this development stage, decreases in $F_{\mathrm{v}}{ }^{\prime} / F_{\mathrm{m}}{ }^{\prime}$ and $\phi_{\mathrm{PSII}}$ were followed by the slight increase (but not significant) in $L_{\mathbb{N B}}$ corroborating the statement made by $L u$ et al. (2002) and Stefanov and Terashima (2008). qNP was higher in BRS Pelota until $6 \mathrm{DAH}$. However, it values were lowering in BRS Pelota from 36 DAH until 48 DAH (Figure $3 C$ ). $q P, L_{D}$ and $L_{N P}$ were unchanged in both rice varieties by senescence (data not shown).

The results of this study show that the fast $\mathrm{Chl} \mathrm{a}$ fluorescence transient measurements with high time resolution provide a non-invasive and rapid method to study PSII activity changes caused by senescence. Since senescence induces structural disorganization, a general trend in the disorganization of the photosynthetic apparatus during senescence could be visualized in rice varieties differing in yield capacity. In addition, although this manuscript does not focused in explain the differences in grain yield of rice cultivars by means of chlorophyll fluorescence investigations, concerning the physiological significance of the senescence and its relationship with assimilate partitioning in plants, we suggest that the higher productivity of BRS Pelota rice cultivar results from its higher assimilate mobilization ability (Falqueto et al. 2009b), in despite of its lower light absorption capacity. These results are supported by that lowest $\mathrm{Chl}$ content and lower values of $\mathrm{Pl}_{\mathrm{ABS} \text {, Total, }}$ $\mathrm{TR}_{0} / \mathrm{ABS}, \mathrm{ET}_{0} / \mathrm{ABS}, \mathrm{ET}_{0} / \mathrm{TR}_{0}$, the amount of photosynthetic reaction centres per absorption ( $\mathrm{RC} / \mathrm{ABS})$ and higher $\mathrm{F}_{0}$, $\mathrm{DI}_{0} /$ $\mathrm{RC}$, specific fluxes for trapping $\left(\mathrm{TR}_{0} / \mathrm{RC}\right)$, electron transport $\left(\mathrm{ET}_{0} / \mathrm{RC}\right)$ obtained in BRS Pelota during senescence (mainly at $46 \mathrm{DAH})$.
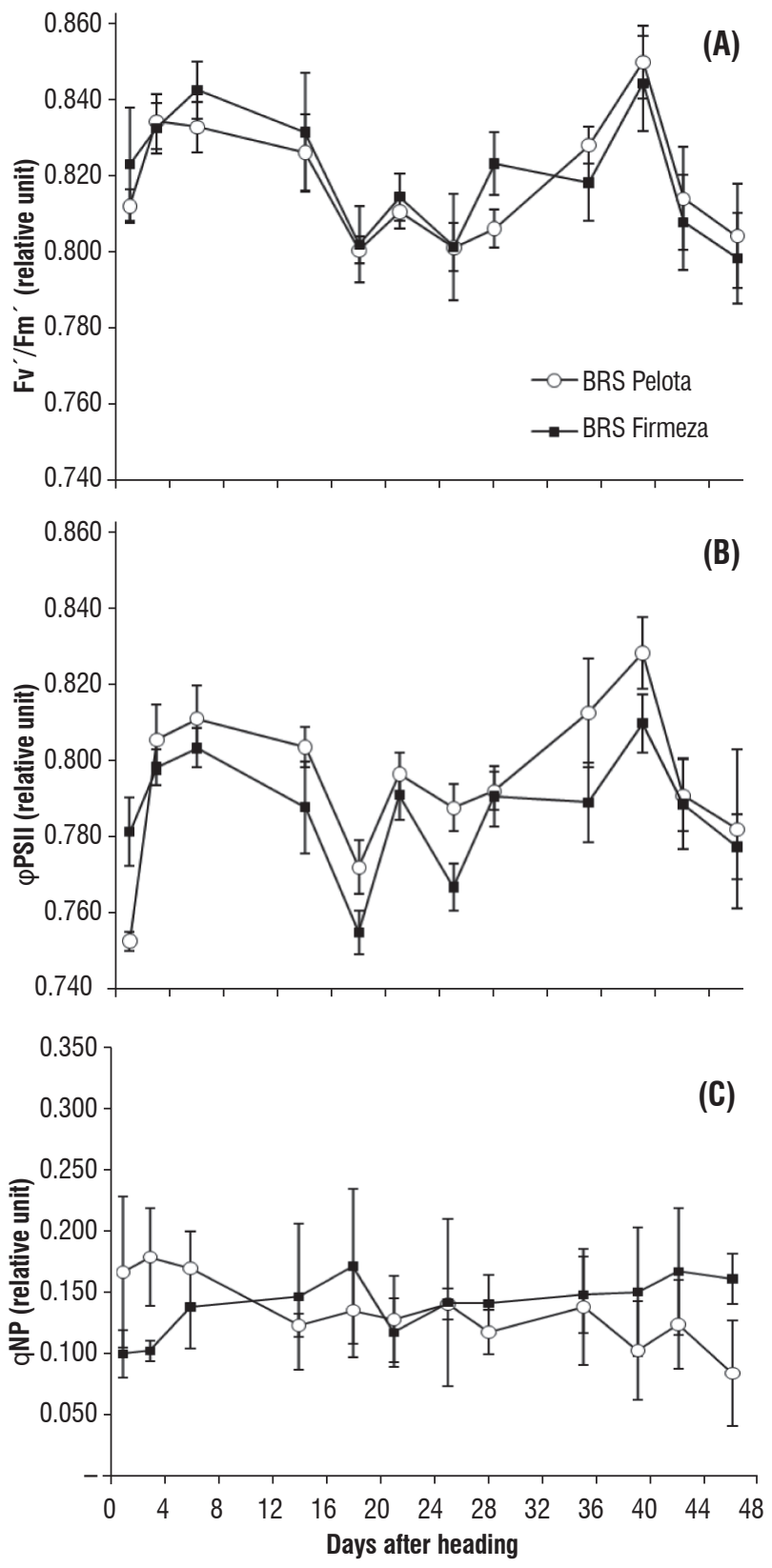

Figure 3. Effective efficiency of PSII photochemistry, when PSII reaction centers were open $\left(F_{v}{ }^{\prime} / F_{m}\right)(A)$, actual PSII efficiency $\left(\phi_{P S I I}\right)(B)$, and nonphotochemical quenching coefficient (qNP) (C) during flag leaf senescence of BRS Pelota, a high yield rice variety (open circle) and BRS Firmeza (filled square), a low yield rice variety rice. Values represent \pm S.E. of ten independent samples at the same time.

The results of this study showed that rice varieties differing in grain yield were characterized by significant differences in the capacity of absorption and use of light. BRS Pelota, the rice cultivar with higher grain yield capacity was characterized by lowest $\mathrm{Chl}$ content and lower values of $\mathrm{Pl}_{\mathrm{ABS}, \mathrm{Tota}}, \mathrm{TR}_{0} / \mathrm{ABS}$, 
$\mathrm{ET}_{0} / \mathrm{ABS}, \mathrm{ET}_{0} / \mathrm{TR}_{0}$, the amount of photosynthetic reaction centres per absorption (RC/ABS) and higher $\mathrm{F}_{0}, \mathrm{Dl}_{0} / \mathrm{RC}$, specific fluxes for trapping $\left(\mathrm{TR}_{0} / \mathrm{RC}\right)$, electron transport $\left(\mathrm{ET}_{0} /\right.$ $\mathrm{RC}$ ). These results show that the decreased photosystem II activity, evaluated through chlorophyll fluorescence analysis, was resultant of leaves senescence process, which was much more expressive in BRS Pelota rice variety. We suggest that the higher productivity of BRS Pelota rice cultivar could be more correlated with energy usage efficiency or assimilate mobilization rather than with their light absorption capacity.

\section{REFERENCES}

Bilger W, Björkman 0 (1990) Role of the xanthophyll cycle in photoprotection elucidated by measurements of light-induced absorbance changes, fluorescence and photosynthesis in leaves of Hedera canariensis. Photosynthesis Research 25:173-185.

Cassol D, Silva FSP, Falqueto AR, Bacarin MA (2008) An evaluation of nondestructive methods to estimate total chlorophyll content. Photosynthetica 46:634-636.

Counce PA, Keisling TC, Mitchell AJ (2000) A uniform, objective, and adaptative system for expressing rice development. Crop Science 40:436443.

Demmig B, Björkman $O$ (1987) Comparison of the effect of xcessive light on chlorophyll fluorescence $(77 \mathrm{~K})$ and photon yield of 02 evolution in leaves of higher plants. Planta 171:171-184.

Demmig-Adams B (1990) Carotenoids and photoprotection in plants. A role for the xanthophyll zeaxanthin. Biochemistry Biophysics Acta 1020:1-24.

Falqueto AR, Cassol D, Magalhães Junior AM, Oliveira AC, Bacarin MA (2009a) Physiological analysis of leaf senescence of two rice cultivars with different yield potential. Pesquisa Agropecuária Brasileira 44:695-700.

Falqueto AR, Cassol D, Magalhães Junior AM, Oliveira AC, Bacarin MA (2009b) Crescimento e partição de assimilados em cultivares de arroz diferindo no potencial de produtividade de grãos. Bragantia 68: 563-571.

Genty B, Briantais JM, Baker NR (1989) The relationship between the quantum yield of the photosynthetic electron transport and quenching of chlorophyll fluorescence. Biochemistry Biophysics Acta 990:87-92.

Jiang H, Wang X-H, Deng Q-Y, Yuan L-P, Xu D-Q (2002) Comparison of some photosynthetic characters between two hybrid rice combinations differing in yield potential. Photosynthetica 40:133-137.

Jiao D, Ji B, Li X (2003) Characteristics of chlorophyll fluorescence and membrane-lipid peroxidation during senescence of flag leaf in different cultivars of rice. Photosynthetica 41:33-41.
Lu Q, Lu C, Zhang J, Kuang T (2002) Photosynthesis and chlorophyll a fluorescence during flag leaf senescence of field-grown wheat plants. Journal of Plant Physiology 159:1173-1178.

Mishev K, Stefanov D, Ananieva K, Slavov C, Ananiev ED (2009) Different effects of dark treatment on pigment composition and photosystem I and II activities in intact cotyledons and primary leaves of Cucurbita pepo (zucchini). Plant Growth Regulation 58:61-71.

Rapacz M (2007) Chlorophyll a fluorescence transient during freezing and recovery in winter wheat. Photosynthetica 45:409-418.

Roháček K (2002) Chlorophyll fluorescence parameters: the definitions, photosynthetic meaning, and mutual relationships. Photosynthetica 40:1329 .

Srivastava A, Strasser RJ (1996) Stress and stress management of land plants during a regular day. Journal of Plant Physiology 148:445-455.

Stefanov D, Terashima I (2008) Non-photochemical loss in PSII in highand low-light-grown leaves of Vicia faba quantified by several fluorescence parameters including $L_{N B} F_{0} / F_{m}$, a novel parameter. Physiologia Plantarum 133:327-338

Strasser A, Tsimilli-Michael M, Srivastava A (2004) Analysis of the fluorescence transient. In: Papageorgiou GC, Govindjee (eds.). Chlorophyll fluorescence: A signature of photosynthesis. Advances in Photosynthesis and Respiration Series, pp. 321-362. Dordrecht: Springer.

Strasser RJ (1981) The grouping model of plant photosynthesis: heterogeneity of photosynthetic units in thylakoids. In: Akoyunoglou $\mathrm{G}$ (ed.). Photosynthesis III. Structure and Molecular Organisation of the Photosynthetic Apparatus, pp.727-737. Philadelphia: Balaban International Science Services.

Tang Y, Weng X, LU C (2005) Differential changes in degradation of chlorophyll-protein complexes of photosystem I and photosystem II during flag leaf senescence of rice. Plant Physiology and Biochemistry 43:193-201.

Tsimilli-Michael M, Strasser R (2008) In vivo assessment of stress impact on plants' vitality: applications in detecting and evaluating the beneficial role of Mycorrhization on host plants. In: Varma A (ed.) Mycorrhiza: State of the art, genetics and molecular biology, ecofunction, biotechnology, eco-physiology, structure and systematics, pp.679-703. 3rd ed., Springer.

Weng X-Y, Xu H-X, Jiang D-A (2005) Characteristics of gas exchange, chlorophyll fluorescence and expression of key enzymes in photosynthesis during leaf senescence in rice plants. Journal of Integrative Plant Biology 47:560-566.

Yordanov I, Goltsev V, Stefanov D, Chernev P, Zaharieva I, Kirova M, Gecheva V, Strasser RJ (2008) Preservation of PS II Electron Transport from SenescenceInduced Inactivation in Primary Leaves after Decapitation and Defoliation of Bean Plants. Journal of Plant Physiology 165:1954-1963.

Zhang CJ, Chen GX, Gao XX, Chu CJ (2006) Photosynthetic decline in flag leaves of two field-grown spring wheat cultivars with different senescence properties. South African Journal of Science 72:15-23. 